\title{
Climate Change and Conservation Biology as it Relates to Urban Environments
}

\section{Cambio Climático y Biología de la Conservación en Relación con los Entornos Urbanos}

SAMANTHA NOLL (Washington State University) \& MICHAEL GOLDSBY (Washington State University)

Artículo recibido: 1 de mayo de 2019

Solicitud de revisión: 2 de noviembre de 2019

Artículo aceptado: 13 de diciembre de 2019

Noll, Samantha \& Goldsby, Michael (2020). Climate Change and Conservation Biology as it Relates to Urban Environments. Recerca. Revista de Pensament i Análisi, 25 (2), pp. 55-71.

\section{Abstract}

Climate change continues to have recognizable impacts across the globe, as weather patterns shift and impacts accumulate and intensify. In this wider context, urban areas face significant challenges as they attempt to mitigate dynamic changes at the local level - changes such as those caused by intensifying weather events, the disruption of critical supplies, and the deterioration of local ecosystems. One field that could help urban areas address these challenges is conservation biology. However, this paper presents the argument that work in urban contexts may be especially difficult for conservation biologists. In light of current climate change predictions, conservation biology may need to abandon some of its core values in favor of commitments guiding urban ecology. More broadly, this essay aims to reconcile the goals of restoration and conservation, by reconceptualizing what an ecosystem is, in the context of a world threatened by global climate change.

Keywords: Philosophy of the City, Climate Change, Conservation Biology, Environmental Philosophy, Restoration.

\section{Resumen}

El cambio climático continúa teniendo impactos reconocibles al través del globo, mientras los patrones meteorológicos cambian y los impactos se acumulan e intensifican. En 
un contexto más amplio, las áreas urbanas sostienen desafíos significados mientras intentan mitigar cambios dinámicos en el nivel local -cambios como los que son causados por la intensificación de eventos climáticos, la interrupción de provisiones críticos y el deterioro de los ecosistemas locales. Una disciplina que podría ayudar enfrentar estos desafíos a las áreas urbanas es la biología de la conservación. A la luz de las actuales predicciones del cambio climático, la biología de la conservación, como disciplina, podría tener que abandonar algunos de sus valores fundamentales a favor de los compromisos que guían la ecología urbana. En términos más generales, este artículo pretende reconciliar los objetivos de restauración y conservación mediante la reconceptualización de lo que es un ecosistema, en el contexto de un mundo amenazado por el cambio climático global.

Palabras clave: filosofía de la ciudad, cambio climático, biología de la conservación, filosofía ambiental, restauración.

\section{INTRODUCTION}

Climate change continues to have recognizable effects across the globe, as weather patterns shift and impacts accumulate and intensify (Nelson et al., 2013; EPA, n.d.). In this wider context, urban areas (including cities, towns, and suburbs) face significant challenges as they attempt to mitigate dynamic changes at the local level - changes such as those caused by intensifying weather events, the disruption of critical supplies, and the deterioration of local ecosystems (World Bank, 2010; Noll, 2018). Addressing these effects is particularly important, as over half the world's population currently lives in urban contexts, and this number is projected to grow by nearly two-thirds by the middle of this century (UN, 2017). In addition, these built environments are large contributors of greenhouse gas emissions (GHGs), as urbanization and GHGs are strongly correlated (Sethi \& de Oliveira, 2015). Thus, urban zones are both a major driver of climate change and face significant challenges due to climate change (Goldsby, 2019).

However, according to Goldsby (2019), cities (at least in the US) also have the economic assets to fund large-scale climate change strategies and residents are more likely to be politically receptive to climate action. Indeed, urban communities play an increasingly prominent role in climate change mitigation

\footnotetext{
It is often useful to distinguish between cities and urban areas. An urban area is typically understood as the human-dominated environment that includes and surrounds urban morphology, such as suburbs, towns, and cities, whereas the term city, which is a fixture of urban areas, is typically reserved for the built environment where there is concentration of human structures. With regard to our argument, both cities, in particular, and urban areas, more generally, have an impact on activities aimed at preserving ecosystem services. The impacts from both are similar enough to allow the terms to be used interchangeably. However, we recognize the distinction between these two concepts.
} 
and adaptation efforts (Kousky \& Schneider, 2003; Rosenzweig et al., 2010; Sharp et al., 2011). In particular, cities (as part of urban zones) across the globe are creating and adopting "sustainability" plans in an effort to reduce climate change impacts on urban citizens, ecologies, and infrastructure. These proposals are by necessity contextual, but they predominantly share the two common strategies of a) mitigation, i.e., the reduction of greenhouse gas emissions, and b) adaptation, i.e., ameliorating the local impacts of climate change. This second strategy is usually the driver for proposals to update severe weather emergency plans, shift land-use patterns in such a way as to limit the impact of flooding, and/or the implementation of "sustainability initiatives," that are aimed at increasing the numbers of green roofs and buildings (Ostrander \& Oliveira, 2013; Gomez et al., 2017). Consequently, urban zones are both a major cause and potentially a major solution to climate change. Thus, environmental ethics cannot afford to ignore these contexts (Light, 2001; Goldsby, 2019; Noll, 2018).

Sustainability plans often include strategies aimed at ameliorating negative impacts on ecosystem "structures," ecological services, and biodiversity levels (Grimm et al., 2013; Scheffers et al., 2016). In other words, reducing global and local impacts of climate change includes more than reducing emissions or increasing the numbers of green buildings. This is imperative, as fixtures of urban zones, such as cities, often negatively impact the environment, even without taking climate impacts into account. Tremblay and St. Clair (2011) argue that "urbanization represents a major threat to biodiversity worldwide because it causes permanent degradation and fragmentation of biologically rich natural communities" (679). Habitat fragmentation and loss associated with urban development have been connected to extinction events and population declines of several native taxa (Crooks, Suarez \& Bolger, 2004; Gnanadesikan et al., 2017). In other words, protecting ecosystems must figure into urban planning. In this context, climate change could exacerbate the situation, as a plethora of species are expected to shift their ranges in response to climate change (Botkin et al., 2007; Bellard et al., 2012). This is problematic for urban contexts, as it could increase the numbers of novel or "invasive" species moving into and through the urban domain. Moreover, these areas are known to act as barriers to migration - barriers that could contribute significantly to the numbers of extinction events (Palmer \& Larson, 2014). In a recent paper, this led Noll (2018) to argue that "urban residents have the potential to play a key role in helping to facilitate ecological resilience of wilderness areas and ecosystems 
beyond the city by helping ensure the migration of nonhuman climate refugee populations" (Noll, 2018: 24). This can be achieved through the use of wildlife corridors, green roofs, and other strategic infrastructure modifications. Thus, conservation efforts in rural areas may be dependent on activities in urban contexts, such as the enhancement of habitats for native species and increasing landscape connectivity. However, these activities are typically counted as restoration-aimed activities. There is some concern among environmentalists that certain restoration-aimed activities should be avoided or subordinated to conservation-aimed activities.

One field that could help urban areas better achieve the two common goals of reducing local and global impacts is conservation biology, as it is charged with the important job of managing ecosystems impacted by human activities and often takes on the tasks of developing, recommending, and implementing species and ecosystem management plans and strategies (Sandler, 2012). However, this paper presents an argument that work in urban contexts may be especially difficult for conservation biologists, as such projects could require both the violation of key values guiding the profession and the acceptance of approaches traditionally disfavored by the discipline. In light of current climate change predictions, conservation biology, as a discipline, may need to abandon some of its core values in favor of commitments guiding urban ecology, such as restoration and remediation.

The aim of this essay is to provide a robust theoretical foundation for mitigating environmental impacts in the city and in wilderness areas outside of urban limits, as these areas play an important role in both. We go so far as to sketch a new conceptual framework for understanding the conservation of wilderness ecosystems. In this way, the essay is interdisciplinary in nature, as it places conservation biology, community ecology, environmental philosophy, and philosophy of the city in conversation with one another. This theoretical work is important, as current philosophers have largely ignored the subject of the city and the commitments that the presence of cities offer in the Anthropocene (Epting, 2016; Light, 2001; Kirkman, 2004). This essay aims to reconcile the goals of restoration and conservation in the context of a world threatened by global climate change.

It should be noted that we will be using the terms "city" and "urban" interchangeably, as philosophy of the city tends to act as an umbrella for philosophical work on all urban areas (Meagher et al., 2019). However, we recognize that cities are only one type of urban morphology found within built environments. 


\section{CONSERVATION, RESTORATION, MITIGATION, AND ADAPTATION}

Conservation prioritizes the preservation of biological diversity and functioning ecosystems (Dick \& Gusset, 2011). The goal of conservation is to determine the negative impact of human activity on biodiversity and ecosystem functioning, and then to develop strategies to prevent the loss of biodiversity and further damage to ecosystems (Gerber, 2010; Soule, 1996). Conservation tends to be more place-based. Sandler (2012) points out that place-based or in-situ preservation is a preferred outcome for conservation. Urbanization is increasingly occurring in conservation hotspots, or areas where numbers of endangered or threatened species are rapidly declining. Thus, conservation is fast becoming a priority for urban management (McPhearson et al., 2016).

Restoration currently plays an important role in urban areas and one could argue that cities should focus on restoration, rather than conservation. The aim of restoration is to return an ecosystem to its unperturbed state or to build a new ecosystem that is functionally equivalent to the vanishing ecosystem in an area where it is no longer threatened. Thus, at the basic level, restoration projects aim to "restore" ecosystem functionality, although restoration projects are unconcerned with the provenance of place related to the ecosystem. As urban environments are heavily marked by human activities, restoration projects do and should play an important role in maintaining ecosystem functioning and integrity in urban areas, because it is often too late to conserve the initial ecosystems. We agree with the scientific (Wang et al., 2011; Frost \& Hyman, 2011) and philosophical literature (Light, 2001; Sandler, 2012) that restoration ecology should play more of a role in urban contexts.

Restoration and conservation are goals that must of necessity be placed in the context of climate change. There are two broad strategies that may be adopted to deal with climate challenges - mitigation and adaptation. Mitigation strategies are used to reduce the impact of human activities on the climate system and individual environments (FAO, 2009; Marshall, 2001). If human activities can be modified so as to reduce their impact on the global climate system, then negative climate impacts can be reduced, offset, or avoided. Given that much of the threat to ecosystem functioning and biodiversity is or will be the result of anthropogenic climate change, mitigation plays an important part in restoration and conservation activities. 
As urban areas have a substantial ecological footprint and impact ecosystems in complex ways, mitigation strategies are key to helping urban and wilderness ecologies survive and thrive (see Table 1).

Adaptation strategies, on the other hand, aim to adjust coupled human and natural systems to function in new climate realities. Some climate impacts are now unavoidable, and adaptation strategies will need to be enacted in order to maintain not only human well-being, but also to maintain a natural system's capacity to provide the ecosystem services that human and nonhuman life depends upon. Any extant ecosystem, and any restored ecosystem, will face new climate challenges in the coming years. In the city in particular, urban ecosystems will need to adapt in order to maintain functioning, as the climate changes and urban populations increase. However, growing cities will have impacts on wilderness ecologies; so planners must consider those impacts as well. Thus, adaptation is a strategy that must be pursued for both restoration and conservation (see Table 1 ).

\section{Table 1}

Possible interactions between the goals and strategies of climate-focused ecosystem management

\begin{tabular}{|l|l|l|}
\hline & $\ldots$ restore & $\ldots$ conserve \\
\hline $\begin{array}{l}\text { Mitigation is a } \\
\text { strategy used } \\
\text { to ... }\end{array}$ & $\begin{array}{l}\text { Avoiding, reducing, or offsetting } \\
\text { climate stressors to an ecosystem in } \\
\text { order to repair or restore said } \\
\text { ecosystem. }\end{array}$ & $\begin{array}{l}\text { Avoiding, reducing, or offsetting } \\
\text { climate stressors to an ecosystem } \\
\text { to protect it from further damage. }\end{array}$ \\
\hline $\begin{array}{l}\text { Adaptation is } \\
\text { a strategy used } \\
\text { to ... }\end{array}$ & $\begin{array}{l}\text { Adjusting land usage to "restore or } \\
\text { replace endangered or extinct } \\
\text { ecosystems in areas where they will be } \\
\text { less threatened by climate stressors in } \\
\text { order to maintain ecosystem services. }\end{array}$ & $\begin{array}{l}\text { Adjusting currently endangered } \\
\text { ecosystems such that the } \\
\text { ecosystem may weather increased } \\
\text { climate stress. }\end{array}$ \\
\hline
\end{tabular}

\section{TO RESTORE OR CONSERVE}

When considering climate action in relation to conservation and restoration, we understand each particular climate action as a strategy to 
achieve one of the two goals of restoration or conservation. One may think that one strategy is better suited for one goal than another. Yet, that need not be the case (see Table 1). For example, climate change is increasingly correlated with species loss, migration interruptions, and species moving into new ecosystems or the proliferation of invasive species, as temperatures change and ideal climate zones shift (Palmer \& Larson, 2014). For urban contexts, this means that mitigation and adaptation efforts will need to simultaneously balance the mitigation of climate stressors on urban environments, while adjusting land usage to maintain ecosystem functioning. Moreover, we are now well past the time where one climate strategy or the other will be sufficient (USGCRP, 2018). Even when one recognizes that climate action will require both mitigation and adaptation, the question remains whether ecosystems should be conserved or restored.

Some have argued that conservation should be preferred over restoration. In particular, some philosophers have worried that complete restoration is impossible or even inappropriate. For example, Robert Elliot (2002) argues that even if it were possible to restore a particular ecosystem such that it would be identical to the original ecosystem at the molecular level (a proposition bordering on the absurd), part of its value would be lost. Indeed, the value of that ecosystem, according to Elliot, lies in the evolutionary and natural history that has given rise to it in the first place. This means that the restored ecosystem, no matter how good it is, would not have the same value as the original ecosystem. Therefore, as Elliot would argue, we ought to prefer the preservation or conservation of "natural" ecosystems to their reconstruction.

In a similar vein, Eric Katz (2003) argues that a reconstructed or restored ecosystem is, in a very real way, a human artifact; nevertheless, he further argues that the naturally occurring ecosystem is not. Katz ultimately worries that restoring or reconstructing ecosystems is inappropriately inserting anthropocentric values into nature. That in turn, he argues, is a violation of Paul Taylor's (1986) principle of non-interference, which includes two duties: (1) we ought not through action or policy place restrictions on the individual organisms that make up an ecosystem; and (2) we ought to adopt a "hands off" policy with regard to ecosystems and biotic systems. The upshot of the principle of non-interference, according to Katz, is that we ought to allow nature to restore itself whenever and wherever we can.

While we sympathize, respect, and even admire the positions of those like Katz, Elliot, and Taylor, who insist that conservation ought to be preferred to 
restoration, we are of the opinion that it is too late to pursue conservation only. If we wish to prevent further loss to biodiversity, and maintain adequate ecosystem services, then some restoration may be necessary. Whether we like it or not, human activity is the most significant factor affecting the climate and it will continue to be the major driver for the foreseeable future. By extension, that means that human activity is also the major force that will shape the biosphere for some time to come. It is the truth of those two claims that led some to suggest that the current epoch is best characterized as the Anthropocene (Grusin, 2017). In the Anthropocene, Taylor's principle of noninterference, while morally preferable, cannot be applied as universally and absolutely as we would like. We broke it; we bought it. Just as with climate change, where we must both mitigate and adapt, with regard to the two goals, we must pursue both conservation and restoration to preserve biodiversity and sustain ecosystem services.

If we are really living in the Anthropocene, the battle to prevent nature from becoming a human artifact may already be lost. That does not mean that we should throw in the towel. Nor does it mean that restoration will make matters worse. John Basl (2010) suggests that restoration can be done in a way to repair the relationship between humans and nature. He argues that some restoration activities may have a remediative quality that will improve our behavior. We think that such activities may go far in bridging the gap between conservation and restoration.

As Young (2000) argues, restoration and conservation can be understood as two sides of the same coin, in that they share several key biodiversity goals, although they utilize strikingly different focuses. For instance, ecological restoration is concerned with restoring or revitalizing the integrity of damaged ecosystems (Balaguer et al., 2014), while conservation prioritizes the preservation of biological diversity and functioning ecosystems (Dick \& Gusset, 2011). As climate change has local and global impacts on ecosystems, both the restoration of damaged ecosystems and the preservation of functioning environments will be required. Restoration and conservation are conceptually connected to the point where there is some disagreement concerning whether ecological restoration should be understood as a management goal (Sandler, 2012) utilized by conservationists or by restorationists (Cairns \& Heckman, 2003; Young, 2000).

\section{ESSENTIALIST THINKING IN CONSERVATION BIOLOGY}


Conservation biology tends to favor place-based preservation, as a management goal. The link between normative postulates guiding this discipline and its favored goal is straightforward. The historical position is that native species are better at maintaining the ecological integrity of the ecosystem in which they evolved and thus the ecological situatedness of the species has value (as described by Sandler, 2012). According to this view, value lost is bad, and value preserved is good. The thought is that species are historically and ecologically situated, species can only be fully preserved within the current location where they live. Finally, this view tends to hold that independence from human control adds value to the ecosystem and thus adds credence to the view that protecting biodiversity against negative human impacts is good (Sandler, 2012).

There is an interesting essentialist assumption that seems to be underwriting this view. According to a standard textbook, an ecosystem is defined as "the biotic community and its abiotic environment, functioning as a system" (Smith \& Smith, 2012). Unpacking that definition reveals that an ecosystem consists of three basic elements: (1) the constituent populations, (2) the environment that supports those populations, and (3) the functional relationship between (1) and (2). It borders on trivial to mention that the constituent populations of an ecosystem and their functional relationship to the environment are dynamic. Thus, it is often assumed that the one constant with regard to ecosystems is the environment, which is typically understood as spatially fixed. As a result, it is tempting to identify particular ecosystems with particular locations, which can explain why conservationists prefer placebased conservation. ${ }^{2}$ Under such an assumption, local extinctions are real extinctions. Moreover, while some change in the other two elements can be tolerated, a change in place is rarely tolerated according to the historical position. Thus, according to the historical position, spatial location is an essential component of an ecosystem.

We do not deny that place has value, but we do think that the historical position's obsession with place is problematic. First of all, the insistence on identifying an ecosystem with a place does not reflect the natural history of ecosystems. While ecosystem location may be relatively constant in more recent timeframes, it is not as constant when one considers geologic

We understand the term 'place' to be a particular and defined spatial location. That spatial location can be an urban area (to include cities) or a rural or wilderness area. In the context of the city and increasing urbanization, in which the human-dominated environment expands, wild or rural areas tend to decrease or be displaced. 
timeframes. On the geologic scale, it might be just as plausible and more useful to consider ecosystems as a system of interconnected lineages of populations that migrate spatially over time. Thinking of ecosystems in this way might provide a better target of conservation in times of rapid geological or climatic change. With global climate change, one would expect populations to move toward the poles, as the functional parts of the environment (e.g., suitable climate conditions) move poleward (Palmer \& Larson, 2014). Preserving an ecosystem in a place that is no longer hospitable, functionally, for the constituent populations is likely impossible. Furthermore, it is not the preservation of place that will conserve biodiversity or sustain ecosystem services. It is the other two elements combined with certain functional elements of the environment that is likely to meet these goals. Thus, divorcing conservation from place-based essentialism is a sounder means to achieving conservation goals.

This is especially the case in urban contexts, as climate change further exacerbates the challenges of place-based conservation projects in the city. While the climate has been changing since this planet had a climate to change, the magnitude, uncertainty, and rate of climate change has been accelerating dramatically over the last century. The relative swiftness of these changes is making species and ecological adaptation difficult (Finch et al., 2012). Taking this situation into account, Sandler (2012) argued that in situ or place-based preservation may become difficult, if not impossible, as current habitats and ecosystems come apart or shift. Specifically, he argues that "many species populations are dependent upon specific environmental conditions that will no longer obtain in their current and recent historical locations as a result of global climate change" (59).

If this is the case, then conservation biologists will increasingly face situations where ecosystems shift. This paper agrees with Sandler, but builds off of his critique to identify additional complications that arise due to climate change and the role that cities play in managing them. We also claim that the problem of climate change exposes the conceptual difficulties associated with the identification of ecosystems with particular spatial locations. At the very least, this paper illustrates how both the urban context and climate change problematize (and will continue to problematize) the role that place-based conservation management strategies should play in the future.

There is a theoretical advantage to divorcing the concept of ecosystems from a particular location, as well as some work yet to be done. Moving away 
from a conceptualization of ecosystems as purely place-based could provide much needed clarity when discussing other conservation issues, such as the problem of invasive species. This new theoretical lens could challenge the dominant view that native species should be prioritized over "invasive" species, for example. It could be that as ecosystems shift, with some species going extinct to be replaced by others, we may find ourselves in a situation where the functionality of ecosystem services is dependent upon the inclusion of a previously considered "invasive" species. Thus, projects aimed at addressing climate change impacts could come into conflict with the view that native species should be prioritized and thus challenge the commitments supporting this position.

This would significantly shift current conservation practices on the ground. For example, the International Union for Conservation of Nature (IUCN) takes a strong position concerning invasive species. In particular, they argue that "invasive alien species (IAS) pose a significant threat to biodiversity in Europe... This threat is likely to increase in the future unless meaningful action is taken at all levels to control the introduction and establishment of these species" (IUCN, 2013:12). Cities are particularly vulnerable to invasive species, due to the amount of commercial activities occurring in these contexts. Thus, according to IUCN, metropolitan areas are required to play a central role in dealing with such invasions. In contrast to IUCN's position, challenging conservation's focus on place would mandate that we further assess whether a novel species should be removed, or whether the constituent population is simply moving into an environment where it fulfills an ecological niche, irrespective of its "native" status. Additionally, when faced with climate-induced species migrations, the success of place-based conservation projects in rural areas may be dependent on whether habitat is set aside for displaced populations, as they migrate (Noll, 2018). Thus, one could argue that conservation projects play an important role in mitigating climate impacts both within and without urban areas, especially when historical commitments are challenged. This is one example of how our theoretical framework would mandate changes to urban conservation projects on the ground.

\section{CONCLUSION: PLACED-BASED CONSERVATION \& THE FUTURE OF CONSERVATION BIOLOGY}


Ideally in a context without the threat of global climate change, preserving ecosystems in their native location would be preferred. We do not deny that. However, if given the choice between a healthy ecosystem (as we define it) in a new location and an anemic one in its native location, we prefer the former. That is to say that we hold that place-based conservation where it can be maintained is to be preferred, but it should not be our only goal. Conservation and restoration are two related goals that should both be pursued whenever and wherever we can. However, we argue that it is the system of interconnected lineages that needs to be conserved, and when we have to choose between that and place, we should choose the former. This will require some rethinking and may entail some painful tradeoffs. In the era of the Anthropocene, we can no longer avoid those painful decisions, for if we do, the results may be worse.

As discussed above, urban sustainability efforts generally include the twin aims of a) helping to mitigate larger global impacts of climate change, and b) adapting to or managing local effects. Both necessarily comprise reducing impacts on ecosystems, as the effects of climate change entail a wide range of global and local environmental disturbances, such as the reduction of biodiversity and variety of other changes to ecosystems across the globe (FAO, 2009; Staudinger et al., 2013). In this context, conservation biology is uniquely situated to provide expertise necessary to protect biodiversity and sustain critical ecosystem services. It can develop, recommend, and implement management practices, plans, and strategies with the express aim of conserving ecosystems without being slavishly tied to place.

\section{REFERENCES}

Balaguer, Luis, Escudero, Adrian, Martín-Duque, Jose, Mola, Ignacio \& Aronson, James (2014). The historical reference in restoration ecology: Re-defining a cornerstone concept. Biological Conservation, $176,12-20$.

Basl, John (2010). Restitutive restoration: New motivations for ecological restoration. Environmental Ethics, 32(2), 135-147.

Bellard, Celine, Bertelsmeier, Cleo, Leadley, Paul, Thuiller, Wilfried \& Courchamp, Franck (2012). Impacts of climate change on the future of biodiversity. Ecology Letters, 15(4), 365-377. 
Botkin, Daniel, Saxe, Henrik, Araújo, Miguel, Betts, Richard, Bradshaw, Richard, Cedhagen, Thomas, Chesson, Peter et al. (2007). Forecasting the effects of global warming on biodiversity. BioScience, $57(3), 227-236$.

Bullock, James, Aronson, James, Newton, Adrian, Pywell, Richard \& Rey-Benayas, Jose (2011). Restoration of ecosystem services and biodiversity: conflicts and opportunities. Trends in Ecology \& Evolution, 26(10), 541-549.

Cairns, John \& Heckman, John (2003). Restoration ecology: The state of an emerging field. Annual Review of Environment and Resources, 21(1), 167-189.

Climate-change-and-challenges-for-conservation-Briefing-Paper-No-13.pdf. (n.d.). Retrieved from https://www.imperial.ac.uk/media/imperialcollege/grantham-institute/public/publications/briefingpapers/Climate-change-and-challenges-for-conservation-BriefingPaper-No-13.pdf (Consulted 2o September, 2019)

Crooks, Kevin, Suarez, Andrew \& Bolger, Douglas (2004). Avian assemblages along a gradient of urbanization in a highly fragmented landscape. Biological Conservation, 115(3), 451-462.

Daviter, Falk (2019). Policy analysis in the face of complexity: What kind of knowledge to tackle wicked problems? Public Policy and Administration, 34(1), 62-83.

Elliot, Robert (2002). Faking nature: The ethics of environmental restoration. New York: Taylor \& Francis.

Epting, Shane (2016). Intra-disciplinary research as progress in philosophy: Lessons from philosophy of the city. Philosophia, 44(1), 101-111.

Falk, Donald, Millar, Constance \& Olwell, Peggy (1996). Restoring diversity: strategies for reintroduction of endangered plants. Washington, D.C.: Island Press.

Finch, Deborah, Smith, Max, LeDee, Olivia, Cartron, Jean-Luc \& Rumble, Mark (2012). Climate change, animal species, and habitats: Adaptation and issues. In Finch, Deborah (Eds.). Climate change in grasslands, shrublands, and deserts of the interior American west: A review and needs assessment (60-79). Fort Collins: U.S. Department of Agriculture. 
Food and Agriculture Organization of the United Nations (2009). Coping with a changing climate: Considerations for adaptation and mitigation in agriculture. Rome, Italy: FAO.

Frost, Pete \& Hyman, Glen (2011). Urban areas and the biosphere reserve concept. In Ian Douglas, David Goode, Mike Houck, \& David Maddox (Eds.). The Routledge handbook of urban ecology (549561). New York: Routledge.

Gerber, Leah (2010). Conservation biology. Nature Education Knowledge, $3(10), 14$.

Gnanadesikan, Gitanjali, Pearse, William \& Shaw, Allison (2017). Evolution of mammalian migrations for refuge, breeding, and food. Ecology and Evolution, 7(15), 5891-5900.

Goldsby, Michael (2019). Paradox in the City: Urban Complications Regarding Climate Change and Climate Justice. In Meagher, Sharon, Noll, Samantha \& Biehl, Joseph (Eds.), The Routledge handbook of philosophy of the city (390-400). New York: Routledge.

Gomez, Sergio, Quevedo, Abel \& Urrestarazu, Luis (2017). The role of green roofs in climate change mitigation: A case study in Seville. Building and Environment 123, 575-584.

Grimm, Nancy, Chapin, Stuart, Bierwagen, Britta, Gonzalez, Patrick, Groffman, Peter, Luo, Yigi, Melton, Forrest et al. (2013). The impacts of climate change on ecosystem structure and function. Frontiers in Ecology and the Environment, 11(9), 474-482.

Grusin, Richard (Ed.) (2017). Anthropocene feminism. Minneapolis: University of Minnesota Press.

Gusset, Markus \& Dick, Gerald (2011). The global reach of zoos and aquariums in visitor numbers and conservation expenditures. Zoo Biology, 30(5), 566-569.

IUCN (2013). Invasive alien species: The urban dimension. Retrieved from https://www.iucn.org/content/invasive-alien-species-urbandimension. (Consulted 11 December, 2019).

Katz, Eric (2003). The big lie: Human restoration of nature. In Andrew Light \& Holmes Rolston (Eds.). Environmental ethics (390-398). New York: Blackwell Publishing.

Kirkman, Robert (2004). The ethics of metropolitan growth: A framework. Philosophy \& Geography, 7(2), 201-218.

Kousky, Carolyn \& Schneider, Stephen (2003). Global climate policy: will cities lead the way? Climate Policy, $3(4), 359-372$. 
Lepczyk, Christopher, Aronson, Myla, Evans, Karl, Goddard, Mark, Lerman, Susannah \& MacIvor, Scott (2017). Biodiversity in the city: Fundamental questions for understanding the ecology of urban green spaces for biodiversity conservation. BioScience, 67(9), 799807 .

Light, Andrew (2001). The urban blind spot in environmental ethics. Environmental Politics, 10(1), 7-35.

Marshall, Ross (2001). Application of mitigation and its resolution within environmental impact assessment: an industrial perspective. Impact Assessment and Project Appraisal, 19(3), 195-204.

McDonnell, Mark (2015). Journal of urban ecology: Linking and promoting research and practice in the evolving discipline of urban ecology. Journal of Urban Ecology, 1(1), 1-6.

McDonnell, Mark, Hahs, Amy \& Breuste, Jurgen (2009). Ecology of cities and towns: A comparative approach. Cambridge: Cambridge University Press.

McPhearson, Timon, Pickett, Steward, Grimm, Nancy, Niemelä, Jari, Alberti, Marina, Elmqvist, Thomas \& Qureshi, Salman (2016). Advancing urban ecology toward a science of cities. BioScience, 66(3), 198-212.

Meagher, Sharon, Noll, Samantha \& Biehl, Joseph (2019). The Routledge handbook of philosophy of the city. New York: Routledge.

Miller, James \& Hobbs, Richard (2002). Conservation where people live and work. Conservation Biology, 16(2), 330-337.

Nelson, Erik, Kareiva, Peter, Ruckelshaus, Mary, Arkema, Katie, Geller, Gary, Girvetz, Evan, Goodrich, Dave et al. (2013). Climate change's impact on key ecosystem services and the human well-being they support in the US. Frontiers in Ecology and the Environment, 11, 483893.

Noll, Samantha (2018). Nonhuman climate refugees: The role that urban communities should play in ensuring ecological resilience. Environmental Ethics, 40(2), 23-38.

Ostrander, Calla \& Oliveira, Donald (2013). San Francisco: Climate action strategy. San Francisco: Department of the Environment.

Palmer, Clare \& Larson, Brendon (2014). Should we move the whitebark pine? Assisted migration, ethics and global environmental change. Environmental Values, 23(6), 641-662. 
Rosenzweig, Cynthia, Solecki, William, Hammer, Stephen \& Mehrotra, Shagun (2010). Cities lead the way in climate-change action. Nature, $467(7318), 909-911$.

Sandler, Ronald (2012). The ethics of species: An introduction. Cambridge: Cambridge University Press.

Scheffers, Brett, Meester, Luc, Bridge, Tom, Hoffmann, Ary, Pandolfi, John, Corlett, Richard, Butchard, Stuart et al. (2016). The broad footprint of climate change from genes to biomes to people. Science, $354(6313), 719$-aaf7671.

Sethi, Mahendra, \& de Oliveira, Jose Puppim (2015). From global 'north-south' to local 'urban-rural': A shifting paradigm in climate governance? Urban Climate, 14, 529-543.

Sharp, Elaine, Daley, Dorthey \& Lynch, Michael (2011). Understanding Local Adoption and Implementation of Climate Change Mitigation Policy. Urban Affairs Review, 47(3), 433-457.

Shrader-Frechette, Kristin \& McCoy, Earl (1993). Method in ecology: Strategies for conservation. Cambridge, Mass.: Cambridge University Press.

Smith, Thomas \& Smith, Robert (2012). Elements of ecology. San Francisco: Pearson Benjamin Cummings.

Soule, Michael (1996). Conservation biology: The science of scarcity and diversity. Sunderland, MA: Sinauer \& Associates.

Staudinger, Michelle, Carter, Shaw, Cross, Molly, Dubois, Natalie, Duffy, J. Emmett, Enquist, Carolyn, Griffis, Roger et al. (2013). Biodiversity in a changing climate: a synthesis of current and projected trends in the US. Frontiers in Ecology and the Environment, 11(9), 465-473.

Taylor, Paul. (1986). Respect for nature: A theory of environmental ethics. Princeton: Princeton University Press.

Tremblay, Marie \& St. Clair, Colleen (2011). Permeability of a heterogeneous urban landscape to the movements of forest songbirds. Journal of Applied Ecology, 48(3), 679-688.

United Nations, Department of Economic and Social Affairs (2017). World population prospects: The 2017 revision. New York: United Nations.

US EPA (n.d.). Climate impacts on agriculture and food supply [overviews and factsheets]. Retrieved from: 
https://19january2017snapshot.epa.gov/climate-impacts/climateimpacts-agriculture-and-food-supply_html (Consulted 20 September, 2019)

USGCRP (2018). Impacts, risks, and adaptation in the United States: Fourth national climate assessment, volume II. Retrieved from https://nca2018.globalchange.gov (Consulted ${ }_{11}$ December, 2019).

Wang, Rusong, Downton, Paul \& Douglas, Ian (2011). Toward ecopolis: New technologies, new philosophies, and new developments. In Ian Douglas, David Goode, Mike Houck \& David Maddox (Eds.). Routledge handbook of urban ecology (636-652). New York: Routledge. World Bank (2010). Cities and climate change: An urgent agenda. Washington D.C.: Knowledge Papers no. 10.

Young, Truman (2000). Restoration ecology and conservation biology. Biological Conservation, 92, 73-83. 